\title{
LOS WARINGUEÑOS Y CHIKWATE GRANDE como patrimonio y tradición viva del mundo andino
}

Sabino Arroyo Aguilar

\section{Resumen}

La cuenca de Huancabamba tiene singular importancia para la región norte del Perú por constituir un espacio cultural cargado de mitos, tradiciones, de historia social y cultural, donde los pueblos y el medio ambiente han tejido una cadena de vida y de sistema de valores, en el contexto de la medicina y la religión andina.

\section{Abstract}

The basin of Huancabamba has a singular importance for the northern region of Perú, because of constituting a cultural space loaded of myths, tradition, of social and cultural history, where the people and the environment have built a chain of life and value system, in the context of the medicine and the Andean religion.

\section{Introducción}

Los waringueños son los maestros curanderos de la provincia de Huancabamba, del departamento de Piura, ubicados en la región subtropical del extremo norte del Perú, que limita con la nación vecina de Ecuador (Loja); de ahí, ambas regiones culturales comparten el culto santoral del Señor Cautivo de Ayabaca (Piura-Perú), de la Virgen del Cisne de Loja (Ecuador) y la recurrencia por los afamados curanderos waringueños de Huancabamba.

Son waringueños porque están pactados con el "Encanto de las Waringas", consideradas como las lagunas sagradas de mayor poder al estar asociadas con el 
"Encanto" mayor o Dios andino principal que mora en la montaña central de Chikwate Grande. Este complejo montañoso, el más alto de la región (4 $200 \mathrm{msnm}$ ), no solo es reconocido como el generador de las lluvias de invierno o poseedor de los lagos más fecundos que se deslizan por sus cuatro lados hacia las parcelas de cultivo de las cuencas o como beneficiario de los mejores pastos de la ganadería y derivados de Huancabamba que abastece al mercado de la región; sino, fundamentalmente, está cargada de múltiples tradiciones vivas en el contexto de la medicina y religión andina, también en el

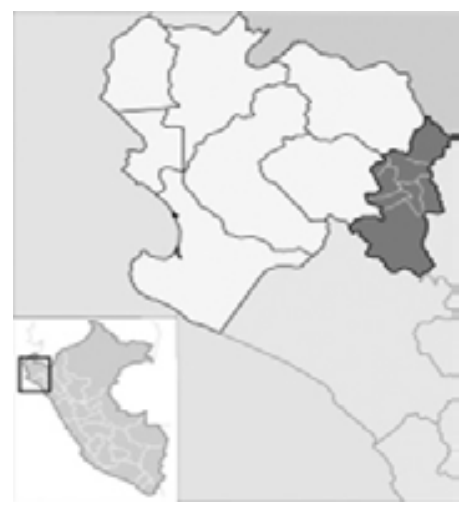
proceso del desarrollo de su historia cultural muy arraigada en la identidad, legitimidad y prestigio de la población huancabambina y de la región de Piura.

\section{Los curanderos Waringueños y las Waringas}

Cuando en la década del 90 realizaba mis primeros viajes a la cálida ciudad de Piura del norte del Perú ${ }^{1}$, uno de los pasajeros manifestaba enfáticamente que hablar de Piura era hablar de Huancabamba y hablar de Huancabamba era hablar de las Waringas y de los waringueños. Entonces, ¿qué significaba ser waringueño o de las Waringas? Los waringueños son los afamados curanderos de Huancabamba alta o Cordillerano y las Waringas son las lagunas sagradas que acordonan a la más alta y mítica montaña Chikwate Grande de Huancabamba, colindante con el territorio de Loja en Ecuador.

Es más, solo las lagunas de esta montaña sagrada recibían el epónimo de las Waringas, las "aguas vivas" con mayores propiedades medicinales para curar o realizar rituales terapéuticos con el fin de cambiar la suerte a los cientos y miles de peregrinos-pacientes que acuden de distintas localidades, regiones y de diversos países. Incluso, otras lagunas existentes en las cumbres de la cordillera occidental y oriental de la jurisdicción norteña, no adoptan el nombre de las Waringas y tampoco gozan del mismo prestigio y uso, aun siendo lagunas sagradas cordilleranas. Esta diferencia jerárquica reside precisamente en la simbología de Chikwate Grande como divinidad principal y montaña sagrada primordial (en la simbología de un palacio o templo repujado de oro y plata de la antigua ciudad) para Huancabamba y la región norte de Perú y para la zona sur de Loja del país vecino de Ecuador.

Entre otros aspectos, me llamó la atención esa mentalidad de los curanderos y lugareños por asignar tanta importancia a las lagunas de las Waringas y, de manera

\footnotetext{
1 Entre 1989 y 1990 dicté cursos de ciencias sociales en la Universidad Nacional de Piura y, desde entonces recorro la región norte realizando mis investigaciones en las provincias de Ayabaca y Huancabamba sobre el culto al Señor Cautivo de Ayabaca y el Curanderismo de Huancabamba, para entender la simbología de los dioses andinos, la configuración étnica y las fronteras culturales (Arroyo, 2004).
} 
implícita, a la montaña sagrada de Chikwate Grande, como dos poderes arcaicos que consagran y autorizan el mejor manejo del poder y del rito de florecimiento de sanación o de cambiar el porvenir a los recurrentes. Por esta razón, el curandero waringueño se preocupa en "compactar" (trato o alianza) con los Encantos o los dioses andinos que moran en dichos espacios sagrados y, con la toma de waychuma (Trichocereus pachanoı) o de "sampedro", oficializa el trato y realiza el viaje astral o se pone en contacto con los dioses para adquirir la sabiduría correspondiente. Entonces, las Waringas son una distinción de poder, una forma de curación y un rito de inmersión distintivo de los maestros waringueños a diferencia de los otros curanderos, pongos, camayoq, alto mesayoq o yatiris de las regiones del centro-sur del Perú, quienes de manera directa invocan a los Apus, Jirkas, Rahus, Aukillos, Orqo Taytacha, Orqo Yaya, Roal, Apusuyo, Achachilas o Dioses andinos (antropológicamente) que moran en las montañas sagradas. Terminologías que difieren de una región a otra con relación al uso lingüístico de la diversidad de los grupos étnicos que aún devienen de la época precolombina y colonial (Arroyo, 1987, 2004).

Gieses (1985) señala que las lagunas de las Waringas son "las famosas" y en la mesa ritual de los curanderos están representadas por las botellas llenas de "plantas mágicas" o de propiedades medicinales recogidas de la jurisdicción de las lagunas y del cerro Chikwate. Son lugares identificados como "misteriosos" y poseedores de "virtudes" o poderes; por ello son respetados, temidos y protegidos por los waringueños y los pobladores de toda la cordillera Wamani (Talaneo y Chulucanas) y de toda la jurisdicción de Huancabamba.

Por la misma razón, cuando Raimondi (1956) se aventura a explorar los ríos afluentes del río Chira del valle de la costa piurana, inicia su viaje de la hacienda de Huangalá en el mes de octubre de 1868, registra el río Quirós y desde este punto asciende al pueblo de Ayabaca, luego se dirige hacia Cumbicus y prontamente llegar a Huancabamba; pero no esperaba lo que acontecería, como dice: "Antes de pasar a esta provincia, hallándome en Cumbicus, solo a tres leguas del río principal que más abajo se llama Quirós quise aprovechar la ocasión para ver su origen; me dirigí para esto a la laguna de Huaringa, situada en la Cordillera y de la cual sale el riachuelo, que forma el brazo principal de este río. Pero para hacer este viaje, yo había contado tan solo con mi deseo, pues no había pensado en las innumerables preocupaciones de los indígenas; ni en todos los obstáculos que estos me pondrían para ocultarme el lugar donde se hallaba esta misteriosa laguna. Lo cierto es, que perdí dos días en aquellas frígidas y desoladas regiones, sufriendo toda clase de intemperies, lluvias, granizadas y violentos ventarrones a manera de huracanas, sin poder conseguir que los Indios, que habitan en miserables chozas, diseminadas en las quebraditas que bajan de la Cordillera, se prestasen a conducirme a la dicha laguna: a pesar de que en mis rodeos había pasado a menos de media legua de distancia. Ya cuando había abandonado la esperanza de conocer la laguna de Huaringa, hallándome en un punto muy elevado, distinguí por atrás y algo lejos la tan deseada laguna, pero el día estaba demasiado avanzado, para tener tiempo de regresar, y así me contenté con saber su existencia y posición” 
(1956: 266-267)². De Huancabamba prosiguió el viaje el 7 de noviembre hacia Jaén, en Cajamarca; solamente cruzando el cerro la Viuda o la Cordillera oriental se llega a la selva de la provincia vecina.

Ahora bien, ¿por qué Raimondi tuvo que pasar tantas incidencias? ¿Por qué los lugareños no le asistieron o le impidieron consumar su deseo? ¿Sería por la intervención de los curanderos waringueños que consideraban a la laguna sagrada, improfanable por los foráneos o extranjeros? En cualquier caso, de todas las lagunas waringueñas, la Negra sigue siendo considerada la laguna más poderosa, la "más brava" y tiene el "Encanto" de mayor poder, especializado en "desatar" o curar todos los males por efectos de la hechicería. Cuando un paciente acude por efectos de la brujería, cualquier curandero huancabambino acudirá al "Encanto" de la laguna Negra; mientras que para la salud o la fortuna recurrirán a la laguna Shimbe y para encontrar pareja o tener hijos se dirigirán a la laguna Palanganas o Arrebiatadas, para el especial rito de florecimiento (Arroyo, 2004). En la zona hay unas 20 lagunas y no todas son utilizadas en la hidroterapia por los maestros curanderos, tampoco son conocidas por la distancia y el temor al frío del páramo de Chikwate.

Raimondi refiere como Waringas solo a la laguna Negra. ¿Sería porque le informaron sobre un río tributario que nacía en dicha laguna? Aunque también las aguas que salen de la laguna Arrebiatadas forman otro tributario del río Quirós. La importancia de la laguna Negra está asociada a los maleficios y, sin embargo, podríamos señalar que su prestigio también se debe a los afamados curanderos waringueños originarios del pueblo de Talaneo y Chulucanas, aún del siglo XIx (Arroyo, 2004). Al parecer, con el desarrollo y ascendencia del pueblo de Huancabamba, la denominación de las Waringas se generaliza para todas las lagunas de Chikwate Grande, como consecuencia de la emigración y operatividad de los propios curanderos mayores de Talaneo y de la jurisdicción del distrito Carmen de la Frontera (Salalá, San Antonio y Sapalache) que residen en la ciudad capital. Aunque, al margen de la movilidad social, el prestigio de los curanderos waringueños está justificada por la importancia de las lagunas Waringas de Chikwate Grande, como ícono representativo de la provincia de Huancabamba y del departamento de Piura.

\section{Simbología de Chikwate Grande y de San Pedro "el Chikwatero"}

El cerro Chikwate Grande es identificado como la montaña cósmica central de la región de Huancabamba por constituir la principal Paqarina (centro de origen), según registra este mito de origen que resumimos:

En los tiempos antiguos existía una ciudad sagrada llamada Chikwate Grande o el pueblo de San Juan de Chikwate. Este pueblo antiguo

2 El texto resaltado es nuestro para dar relevancia a lo sucedido y a la propia apreciación de Raimondi. 
se concibe como una ciudad paradigmática, opulenta y primorosa, donde no había pobreza ni desorden; incluso, hasta sus templos estaban edificados de puro oro y de plata maciza de primera clase, también ahí estarían "embodegadas" todas las riquezas del mundo. Este modelo arcano se habría encantado (ocultado) para resguardar sus tesoros del saqueo de los conquistadores españoles, sus pobladores aseguran que en el futuro cercano se desencantará dicha ciudad enigmática para abastecer de alimento y de riqueza a su gente echada a la pobreza y mendicidad. Incluso, reafirman, ese tiempo ya estaría acercándose o anunciándose con el afloramiento de las "fibras de oro" que emerge y corre en forma líquida por el río Cachiaco de Ninanvalle del lado oriental de Chikwate Grande (Arroyo, 2004).

Este mito se ha convertido actualmente en un pretexto y proyecto alternativo no solo para cuestionar el presente a través del pasado en busca de un futuro mejor; sino, fundamentalmente, es un componente vital para cohesionar a todos los pobladores sin distinción de clase ni rasgo étnico, a organizaciones populares y autoridades locales de la región norte del Perú, que hacen frente a la economía expansiva de las empresas transnacionales de Majas y a la política concesionista de los gobiernos de turno, dentro del marco de legitimidad y derecho cultural de defender su territorio ecológico regional, con el compromiso latente de reivindicar su patrimonio cultural, hoy representado por el curanderismo norteño como ícono de la tradición milenaria.

Es patrimonio cultural y ecológico, por cuanto la montaña de Chikwate Grande es concebida como el aposento del encanto tutelar o dios principal de la región, en el contexto de la medicina y religión andina de acervo cultural que delimita la región norte en complementariedad y competitividad del poderoso encanto Gran Paratón del extremo sur de Huarmaca. Por lo tanto, Chikwate Grande se convierte en la divinidad más influyente que ordena el sistema de vida en la jurisdicción de su amplio entorno, además es

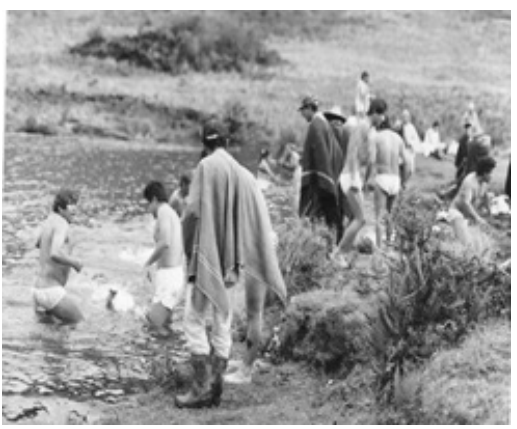
identificado como el fundamento de la vida, aliado, protector y benefactor de sus "gentes", que provee las riquezas, fertiliza las parcelas, fecunda los ganados y alivia a los enfermos. También es el controlador de los truenos y vientos, productor de las nubes de lluvia, almacenador de las aguas en las lagunas de las Waringas, abastecedor de los ríos para el riego y fiscalizador de otros fenómenos naturales y sociales que inciden directamente en la vida de los hombres del norte. Es el dios agricultor, ganadero, curandero, artesano, viajero e incluso comerciante cuando es necesario; asimismo, es patrón principal y gobernante de los pueblos, el padre de familia cargado de hijos, tiene parientes, vecinos y amigos, es líder carismático o consejero oportuno como 
cualquier dios andino; por eso compite con sus homólogos por las aguas de la lluvia, por la tierra o por alguna buena moza, como cualquier hombre. Por consiguiente, Chikwate Grande y el Gran Paratón siempre son reconocidos, les ofrecen sus pagos para curarse, tener abundante cosecha, muchos ganados y buena salud a través del rito del florecimiento en las aguas gélidas de sus Waringas (foto: hidroterapia en la laguna Shimbe).

Seguramente por este significado profundo, la iglesia cristiana, desde la colonia, integró a San Pedro como personaje carismático en la cosmovisión de los waringueños; porque aparece como "la llave" de la encantada ciudad arcana de San Juan de Chikwate Grande, afectuosamente identificado como San Pedro, el Chikwatero (con sombrero de campesino o chikwatero). Pues, según el relato, este santo patrón habíase salvado del encantamiento de la antigua ciudad, debido a que en ese momento se encontraba peregrinando por la lluvia en las tierras altoandinas resecadas, hoy se encuentra en una hornacina de la periferia del templo de Huancabamba y siempre acude a solicitud de su gente. El otro San Pedro grande es de los "mistis" (blancos o del poder local), siempre ocupa el altar central y cuando sale en procesión lo hace solo por las calles principales del pueblo de Huancabamba. Asimismo, hay otro relato aparentemente reciente, donde sindican a un sordomudo que por buscar sus ganados logró ingresar en la ciudad encantada y habría hallado a dicho San Pedro, pequeño y con sombrero al estilo chikwatero. Y cuando el mudo demandaba dinero, portando a San Pedro se dirigía e ingresaba directo a la ciudad de Chikwate Grande para sacar la cantidad requerida de oro, pues era su llave. Otro caso que se asocia es la visión andina, según la cual todos los sordomudos, niños o borrachos siempre dicen la verdad, son considerados en la categoría de los inocentes y gozan de la confianza divina (Ramírez, 1966; Arroyo, 2004).

La figura de San Pedro está asociada a la función del cactus denominado waychuma o sampedro, como elemento primordial para la toma de los curanderos y con ello abrir las hebras del conocimiento andino para el logro del tratamiento eficaz y contacto con los encantos de las lagunas y las montañas sagradas. De modo que, muchos curanderos cubren (cristianizan) o amplían su dominio social asociando su función primaria en relación a las andanzas y chascos de los santos, quienes solo con la toma de waychuma lograron lucidez para recordar o encontrar lo deseado, según rotulan algunos de los siguientes relatos: dicen que la Virgen perdió a Jesús y al tomar sampedro soñó dónde estaba y desde entonces le dio el poder a la planta; también cuentan que Jesús le jugó una broma a San Pedro y escondió la llave del cielo, este lo encontró y supo de lal juego tomando waychuma, en su reconocimiento le hizo su tocayo (Polia, 1994). Además, a la arcana ciudad de Chikwate Grande se le identificó como San Juan Chikwate Grande y dentro de la tradición de los curanderos el 24 de junio marca el día más importante cuando las aguas de las lagunas Waringas adquieren mayores propiedades o poderes curativos y es el tiempo propicio para que muchos curanderos de otras regiones acudan para ser "parados" o "levantados" por los waringueños, "recargarse" de poder y proseguir con sus actividades. De este modo, adaptaron los elementos cristianos a la racionalidad andina, donde la simbología de San Pedro o sampedro representa al portero o la llave del cielo y del mundo 
astral para el manejo y operatividad en el mundo terrenal por los intermediarios cristianos y andinos. Incluso, el día 24 de junio es arraigado en el calendario cristiano y reconocido como la fiesta de San Juan o Día del Campesino, anteriormente el Día del Indio, asociado al Año Nuevo andino del solsticio de invierno y expresado por la fiesta del Intirraymi de Cusco que se extiende a otras regiones por efectos del turismo globalizante.

En la percepción de los huancabambinos, entre otros aspectos, la montaña sagrada de Chikwate Grande es el unificador de la Cordillera Wamani u Occidental, y de la Cordillera Oriental es el contenedor del conjunto de las lagunas sagradas conjuncionadas por el epónimo de las Waringas, es el centro de las cuencas de Huancabamba, Ayabaca, región oriental y también la cuenca de Loja (Ecuador). Incluso, Bernex (1988) geográficamente precisa que al este de Chikwate Grande se formó la cuenca amazónica de Chinchipe irrigado por los ríos tributarios Blanco y Canchis que nacen de Chikwate y desembocan en el río Marañón (y con el río Ucayali forma el gran río Amazonas que desemboca en el Océano Atlántico); al oeste se forma la región cálida costeña u occidental que desciende desde la cuenca de Ayabaca, irrigada por el río Sullana (tributado por el río Quirós que nace en la laguna Negra) y desemboca al Océano Pacífico; al sur se ubica la cuenca Huancabamba-Chamaya, irrigada por el río Huancabamba que nace en la laguna Shimbe y el río Tabaconas que tributan al río Marañón; y al norte se ubica la cuenca sur de Loja, en Ecuador.

De igual manera, Chikwate Grande es el lugar de encuentro de las cordilleras, es el generador de los grandes páramos (lluvia suave y permanente) y aglutinador de las lagunas morrénicas; asimismo, es el centro desde donde se distribuyen los ríos que hacen próspero a los valles y cuencas. Por ello, es considerado como el centro del mundo norteño, como Cusco es el ombligo del mundo sureño; caracteriza al mundo andino de visión "espacio-céntrica" a diferencia del "homocentrismo" del mundo occidental. Este pensamiento andino es homologable en la civilización hindú al Monte Meru, considerado el centro del mundo; al monte Parnaso en la civilización griega; y en México a la montaña sagrada de Popocatépetl, lugar de residencia del dios mayor, donde a sus cuatro lados se ubican las grandes cuencas o llanuras de la civilización náhuatl, incluso hoy los intermediarios conocidos como "tiemperos y graniceros" de Ecatzingo y de Tetela del Volcán invocan a los encantos para la lluvia o dan lectura al tiempo mediante la representación onírica, para de ahí ser identificados como "las sociedades que viven de los sueños" (Benítez, 2010). El "tiempero" o "Misionero del Temporal", Epifanio Alonso Margarita, nos relató el siguiente mito3:

3 Los días 12 y 13 de octubre de 2010 recorrimos con el etnohistoriador Víctor Benítez los pueblos de los municipios de Ecatzingo en el Estado de México y Tetela del Volcán en el Estado de Morelos, ubicados en las falderías y al pie del nevado y volcán de Popocatépetl. Es la región de los pocos especialistas que subsisten desde los tiempos arcanos o de la tradición milenaria, aún atados a la tierra madre generatriz siguen practicando el rito de propiciación por la lluvia al "Encanto" Popocatépetl, divinidad o dios principal de la región que reside en la montaña sagrada de la Sierra Nevada del mismo epónimo (Popocatépetl). Incluso, cerca al volcán existe un gran santuario encubierto por la imagen cristiana 
En los comienzos de formación del mundo, cuatro hermanos aparecen en la región de Morelos y solo uno de ellos llega y se convierte en lo que es hoy el cerro nevado y volcán de Popocatépetl y desde entonces es el centro del mundo, los otros tres no llegaron por quedarse dormidos al descansar y se convirtieron en las tres montañas juntas, ordenadas, de la misma forma y tamaño que se observan desde la altura del pueblo de Tetela. Aunque don "Chevio" (Atanacio Rosales Carmona) de Ecatzingo nos comenta que el "Señor Popocatépetl" habría morado en su zona y nos muestra algunos restos cerámicos prehispánicos sobre la superficie de su parcela y rocas o wankas con incisiones para llenar algún líquido e intercomunicarse con otros orificios cóncavos en las piedras de forma irregular de la zona ${ }^{4}$.

En el lenguaje de Eliade (1968), las montañas sagradas son el Axis Mundi, en el "simbolismo arquitectónico del Centro", donde el cielo y la tierra se encuentran o se juntan; en cambio, en lenguaje andino es el centro del encuentro generacional de los hombres con los muertos y sus dioses o para el emparejamiento (hierogamia) de los Apus con la Pachamama. En este caso, los ríos cumplen la función del semen de los dioses que depositan en el vientre materno — las lagunas Waringas — , fecundas y poderosas, sintetizadas y explicadas por el ecosistema andino. De ahí, el pensamiento y la religión andina, por antonomasia, es la religión ecológica en la figura de la geografía sagrada, para preservar la vida y revalorar el mundo dentro del principio ecológico que rige las interrelaciones de los seres vivos de la naturaleza y evita la destrucción del medio ambiente.

\section{Los Dioses y la medicina andina como patrimonio y tradición viva}

Los dioses andinos que residen en las montañas sagradas, ya de por sí conforman una geografía sagrada con identidad y jurisdicción que representa, clasifica y distribuye a los pueblos andinos; por lo que la palabra "waringas" está cargada de acontecimientos sociales y de hechos culturales que se compaginan en la historia andina de la región norteña desde tiempos inmemoriales. Waringas procede de dos palabras sagradas con connotación de poder: Wari + Inga o Inka. Wari, espíritu o dios de poder asombroso

\footnotetext{
y peregrinada por los especialistas en ciertas épocas del año.

Mi viaje a México, por invitación de representantes del Instituto Nacional de Antropología e Historia para dar las conferencias sobre la religiosidad andina y la configuración étnica, se tradujo en el inicio de las investigaciones antropológicas y etnográficas, y dentro de ese marco viajamos, con el colega Eduardo Corona, a los santuarios de la Virgen de Guadalupe, del Señor de Chalma y a la cuenca de los afamados curanderos de Tepoztlán. Mientras, con Víctor Benítez visitamos los pueblos de Amecamega, Ecatzingo y Tetela de Volcán, ubicados en la jurisdicción del nevado y volcán de Popocatépetl, considerado "Encanto" o divinidad mayor de esa montaña sagrada.
} 
que se manifiesta en la simbología del viento, agua y trueno (fuego), también con el poder de los "awelos" (ancestros) en los sitios arqueológicos, incluso aún perviven los pueblos étnicos de waris y llacuaces en los barrios del distrito de Huarmaca. Asimismo, en la memoria andina, el Inka sigue siendo el gobernante cusqueño asociado a la simbología de padrillo, semillero o fuerza extraordinaria para destacar el poder social y dominio cultural; tal es el caso que en muchas regiones del Perú subsisten relatos del inka como el rey que desposa a las hermosas ñustas de las comarcas y en gratitud edifica canales de riego en lugares tan ariscos o desiertos, como la huella del tiempo. Por lo tanto, el buen gobernante, en la mentalidad de los campesinos, es aquel que atiende el desarrollo agrario y esto muestra que el Perú sigue siendo una cultura agraria milenaria, al margen del determinismo económico moderno del PBI.

Entonces, la región de Huancabamba está cargada de términos y conceptos del "Inka": sitios arqueológicos de la época inka (Mitupampa, Huancapampa, Cajas, Ushnu Inka, Aypati, etc.), Qapaq Nan o el Camino Inka, laguna del Rey (Baños del Inka), plantas medicinales (misha inka, tabaco del inka), Inqaychu (illas o espíritus del ganado), etc. También el mito de origen de la antigua ciudad de Huancabamba o Huancapampa registra: "En los tiempos antiguos ciudad de Huancapampa fue atacado por el Rey Blanco desde el cerro Witiligún, hiriendo mortalmente al Rey Inka, quien clama venganza a su padre, el Dios Sol, que la convirtió en la actual montaña sagrada de Pariaqaqa". (Ramírez, 1966; Arroyo, 2004) y hoy es Apu tutelar de los afamados curanderos waringueños de Huancabamba.

Los curanderos, para legitimar su poder y prestigio, además de reafirmar su pacto con los encantos de las Waringas y de Chikwate Grande, se reactualizan y acrecientan su prestigio y poder de la "mesa" y las "artes" de los "Shununas" o Anshununas" (instrumentos de varas, espadas, flechas o lanzas que conformarían la mesa de los duendes de los ríos), de los "brujos moros" (curanderos waringueños prehispanos) hallados en las cuevas o entierros arqueológicos y también se identifican como originarios de la "raza abolengo" o proceden de las antiguas familias reconocidas de curanderos (Polia, 1988; Arroyo, 2004). Todas estas atribuciones refuerzan al prestigio de los waringueños para destacar ante los curanderos "maleros" de Salas (Chiclayo), de La Libertad o de otras regiones y empequeñecerlos dentro de la competencia y mercado de la medicina andina del norte peruano. Incluso, las hierbas medicinales waringueñas tienen mucha acogida en los mercados de las urbes de Piura, Chiclayo, Lima y del extranjero; aunque su tala indiscriminada por los "hierberos" y comerciantes ya viene afectando con la escasez para los curanderos.

En el contexto de la medicina andina peruana, los curanderos de Huancabamba se distinguen por ser depositarios conscientes de las tradiciones milenarias de origen precolombino y colonial, de ubicarse en la región subtropical con cualidades especiales, ser poseedores de las lagunas y montañas sagradas atribuidas con fuerza mística natural y cultural que los forma, fortalece y acrecienta su prestigio, con una personalidad carismática y de líder cultural de waringueños que se empoderan en el mundo de las curaciones o de la salud pública regional andina. De ahí, muchos waringueños emigran a las ciudades de la costa norte y centro del Perú, acrecentando 
su popularidad como curanderos de Huancabamba; mientras de otras regiones se mantienen a nivel local o se hallan en proceso de extinción.

Por esta importancia cultural y de simbolismo religioso que representa la región de Chikwate Grande y sus lagunas sagradas de las Waringas; asimismo, por la personalidad histórica y racionalidad espacio-social de los curanderos waringueños, deben ser reconocidos y declarados como patrimonio cultural y santuario ecológico de la región norte del Perú. Es una forma de reivindicar, salvaguardar y revalorar la cultura de la medicina y religión andina, no como un exotismo extraordinario sino como pensamiento ambiental que aporta a la humanidad con sentido espiritual (sensibilidad moral, social y ética) y juicio de valor (conocimiento ambiental y productividad regulada). Es dar a conocer que las montañas tejen espacios de cadena de vida continua (principio del ecosistema) en la simbología del poder de los dioses andinos emparentados y que las comunidades o los ayllus aún siguen distinguiéndose por la práctica de los principios de reciprocidad y redistribución social andina.

Mientras tanto, los pobladores de Huancabamba, Ayabaca y otros distritos de la zona de confluencia de Chikwate Grande y del tablazo de Piura vienen sosteniendo conflictos y querellas como medios de defensa y reagrupación frente a la estrategia expansiva de la compañía minera inglesa Majas, con la finalidad de evitar los efectos irreversibles de la contaminación ambiental, resguardar la economía campesina y el imaginario colectivo que forman parte de la identidad y legitimidad de Huancabamba-Piura y de la región norte del Perú.

\section{BIBLIOGRAFÍA}

ARROYO, Sabino

2007 "Territorio Sagrado de Pariaqaqa en los distritos sureños de Huarochirí". Revista de Antropología N. ${ }^{\circ} 5$ de la E.A.P. de Antropología de la Facultad de Ciencias Sociales de la UNMSM, Lima.

2007 "Dioses andinos y espacios culturales en los Andes". Runamanta, Revista de Antropología N. ${ }^{\circ} 2$ y 3 del Departamento Académico de Historia, Antropología y Arqueología de la Facultad de Humanidades de la Universidad Nacional Federico Villarreal, Lima.

2006 “Utopía andina o alternativas socioculturales? Sistemas sociales temporales y ciclos culturales de esperanza y proyecto". Revista de Antropología $\mathrm{N}^{\circ} 4$ de la E.A.P. de Antropología de la Facultad de Ciencias Sociales de la UNMSM, Lima.

2005 "La cultura andina es patrimonio y tradición viva". Revista de Antropología $\mathrm{N}^{\circ} 3$ de la E.A.P. de Antropología de la Facultad de Ciencias Sociales de la UNMSM, Lima.

2004 Dioses y oratorios andinos de Huancabamba. UNMSM, Lima. 
1987 Algunos aspectos del culto al Tayta Wamani. Seminario de Historia Rural Andina de la Universidad Nacional Mayor de San Marcos, Lima.

BENÍTEZ, Víctor

2010 Las sociedades que viven de los sueños. El sueño en la vida ritual al pie de los volcanes. Tesis para la Licenciatura en Etnohistoria de la Escuela Nacional de Antropología e Historia, México, D.F.

BERNEX, Nicole y REVESZ, Bruno

1988 Atlas Regional de Piura. CIPCA-PUCP, Lima.

ELIADE, Mircea

1968 El mito del eterno retorno. EMECÉ de Buenos Aires.

GIESES, Claudius

1985 Encantos poderosos y curanderismo en la costa y sierra norte del Perú. Ponencia en el Primer Congreso Nacional de Investigaciones en Antropología, Concytec, Lima.

POLIA, Mario

1994 Cuando dios lo permite: Encantos y arte curanderil. Edit. Prometeo, Perú.

1988 Las lagunas de los encantos. CEPESER, Piura.

RAMÍREZ, Miguel

1966 Huancabamba su historia, su geografía y su folkelore. Piura.

RAIMONDI, Antonio

1956 El Perú. Lima. 